\title{
Influence of severity of illness on neutrophil gelatinase-associated lipocalin performance as a marker of acute kidney injury: a prospective cohort study of patients with sepsis
}

Jill Vanmassenhove ${ }^{1}$, Griet Glorieux', Norbert Lameire ${ }^{1}$, Eric Hoste ${ }^{2,3}$, Annemieke Dhondt ${ }^{1}$, Raymond Vanholder ${ }^{1}$ and Wim Van Biesen ${ }^{*}$

\begin{abstract}
Background: The role of neutrophil gelatinase-associated lipocalin (NGAL) as a diagnostic marker for acute kidney injury (AKI) in sepsis is still debated. We hypothesized that in sepsis, the performance of serum(s) and urinary(u) NGAL can be negatively impacted by severity of illness and inflammation, and that both UNGAL and SNGAL levels can be increased regardless of presence of AKI.

Methods: One hundred and seven patients with sepsis were included. UNGAL and sNGAL were measured at admission (T0) and 4 hours (T4) and 24 hours later (T24). Transient and intrinsic AKI were respectively defined as AKI according to RIFLE during the first 72 hours that did or did not recover to "no AKI" in the following 72 hours. Patients were classified according to tertiles of CRP and APACHE II score increase. The relationship between sNGAL and UNGAL was assessed by linear regression.

Results: Fifty-seven patients developed transient and 22 intrinsic AKI. Prevalence of transient and intrinsic AKI were higher in patients with versus without septic shock (OR (95\% Cl):3.3(1.4-8.2)). UNGAL was associated with sNGAL, and this with parallel slopes but different intercepts for $A K I\left(Y=0.87^{*} X+314.3, R^{2}=0.31\right)$ and no AKI $\left(Y=0.87^{*} X+20.1, R^{2}=0.38\right)$. At T4, median UNGAL and sNGAL levels were higher in septic patients with versus without shock but this is independent of AKI ((545 ng/mL vs $196 \mathrm{ng} / \mathrm{ml}$ for uNGAL and $474 \mathrm{ng} / \mathrm{ml}$ vs $287 \mathrm{ng} / \mathrm{ml}$ for sNGAL (both $\mathrm{P}=0.003)$ ). Both uNGAL and SNGAL levels increased with tertiles of CRP and APACHE II score increase.

Conclusions: Serum and UNGAL levels are influenced by severity of illness and inflammation, and this was found to be independent of the presence of AKI. There is a strong correlation between sNGAL and UNGAL levels in patients with sepsis, indicating that increased levels of UNGAL can also be due to overspill from the systemic circulation, blurring the discriminative value of NGAL as a biomarker for AKI in patients with sepsis.
\end{abstract}

Keywords: Sepsis, Acute kidney injury, NGAL

\footnotetext{
*Correspondence: wim.vanbiesen@ugent.be

${ }^{1}$ Renal Division, Ghent University Hospital, Ghent, Belgium

Full list of author information is available at the end of the article
} 


\section{Background}

Septic acute kidney injury (AKI) is associated with worse outcome compared to non-septic AKI and is regarded as a distinct clinical entity [1]. The unacceptably high mortality rates associated with septic AKI are partly explained by an incomplete understanding of the pathophysiology and a delay in diagnosis [2-6]. Early diagnosis of septic or non-septic AKI remains cumbersome because it relies on imperfect parameters such as serum creatinine while introduction of new serum and urinary biomarkers could hypothetically allow earlier diagnosis and better prognostication [7-9]. At present, NGAL (neutrophil gelatinase-associated lipocalin) has been the most frequently investigated biomarker for early diagnosis of AKI [10]. In humans, three different forms of NGAL can be found, namely a $25 \mathrm{kDa}$ monomer, a $45 \mathrm{kDa}$ dimer and a $135 \mathrm{kDa}$ heterodimer, covalently conjugated with gelatinase [11-13]. Up till now, no commercially available immunoassays are able to make a clear discrimination between the monomer, mainly released from tubular epithelial cells, and the dimer, originating from neutrophils [12].

Some studies found increased urinary NGAL levels in patients classified as having transient AKI, suggesting presence of subtle tubular structural injury [14,15]. In addition, studies where there was a rise in biomarker level (either in serum or urine) without a rise in serum creatinine or a decrease in urinary output, resulted in speculation on the existence of a new entity called $s u b$ clinical AKI [16,17]. However, serum NGAL levels can be increased in many other conditions beside acute kidney injury, such as inflammation [18]. As serum NGAL is filtered at the glomerular level, also urinary NGAL can potentially be influenced by inflammation [19-21].

The present study aims to characterize the origin of the raised serum and urine levels of NGAL in septic patients. We hypothesized that, as in sepsis patients, the prevalence of AKI is related to severity of sepsis, which in turn is associated with an increase in urinary and serum NGAL levels, a correlation between both urinary and serum NGAL, and severity of illness could exist, independent of the presence of AKI.

\section{Methods}

\section{Study cohort}

One hundred and seven consecutive patients with sepsis, admitted to the Ghent University Hospital between $12 / 01 / 2010$ and 05/09/2010, were prospectively enrolled. Sepsis, severe sepsis or septic shock were defined according to the American College of Chest Physicians/Society of Critical Care Medicine Consensus Conference guidelines [22]. Briefly, sepsis was defined when two or more of the following conditions were present as a result of infection: 1) temperature $>38^{\circ}$ or $<36^{\circ}, 2$ ) heart rate $>90$ beats $/ \mathrm{min}, 3)$ respiratory rate $>20$ breaths/min or $\mathrm{PaCO} 2<32 \mathrm{mmHg}(<4,3 \mathrm{kPa})$ or 4$)$ white blood cell count $>12000$ cells $/ \mathrm{mm}^{3}$ or $<4000$ cells/ $\mathrm{mm}^{3}$, or $>10 \%$ immature (band) forms. Severe sepsis was defined as sepsis associated with organ dysfunction, hypoperfusion or hypotension. Sepsis with shock was defined as sepsis with hypotension despite adequate fluid resuscitation or vasopressor need. Since only four patients were not classified as having either severe sepsis or septic shock, we combined sepsis and severe sepsis in a new cumulative category 'sepsis without shock', as opposed to 'sepsis with shock'. Exclusion criteria were 1) a history of liver and/or kidney transplantation, 2) ICU stay less than 24 hours, 3) patients treated with chronic haemodialysis and 4) age $<17$ years.

Fluid management and decision-making for need of RRT were done by intensivists, who were blinded to the study, and according to protocols applied in the study hospital. The study was approved by the ethical committee of the Ghent University Hospital. Written informed consent was obtained from the patient or their next of kin. Research adhered to the tenets of the Declaration of Helsinki.

\section{Study definitions}

We defined AKI based on the worst of either serum creatinine or urinary output criteria according to RIFLE [23]. The urinary output criterion was based on 6-hour blocks, as described by Macedo et al. [24]. Baseline serum creatinine was based on the most recent value before admission or was estimated with the MDRD equation if the latter was not available [23].

Transient acute kidney injury was defined as presence of AKI according to RIFLE, occurring in the first three days after admission and returning to no AKI within the following 72 hours. Intrinsic AKI was defined as presence of AKI according to RIFLE in the first three days of admission that did not improve to no AKI in the following 72 hours. Patients who left ICU before 5 days after admission were followed up at the department they were transferred to.

\section{Sample collection}

Urine and blood samples were collected at the moment of admission (T0), four hours later (T4) and 24 hours later (T24). Blood samples were centrifuged at $1500 \mathrm{~g}$ for 10 minutes within 20 minutes after collection, and serum was aliquoted and stored at $-80^{\circ} \mathrm{C}$ for later batch analysis. Urine was collected in a sterile manner and centrifuged at $500 \mathrm{~g}$ for 10 minutes, and urine samples were aliquoted and stored at $-80^{\circ} \mathrm{C}$ for later batch analysis.

Serum and urinary neutrophil gelatinase-associated lipocalin (NGAL) were measured using an ELISA kit (Bioporto $^{\mathrm{R}}$ Diagnostics Denmark). 


\section{Data collection}

After informed consent, demographics and medical history were obtained. Laboratory and clinical data were registered in a dedicated database. APACHE II scores were calculated over the first 24 hours of admission.

Patients were classified according to tertiles of serum C-reactive protein (CRP) levels (CRP $\leq 20.10 \mathrm{mg} / \mathrm{dL}$, CRP 20.11-30.70 mg/dL and CRP $\geq 30.71 \mathrm{mg} / \mathrm{dL}$ ) and APACHE II score increase (APACHE II $<20$, APACHE II 20-25 and APACHE II >25).

\section{Statistical analysis}

Results are reported as medians and interquartile ranges (IQR) for continuous variables, unless otherwise specified. Discrete variables are reported as numbers and/or percentages. All statistical analyses were performed using SPSS ${ }^{\ominus}$ 19. All consecutive patients fulfilling the inclusion criteria were included, irrespective of their course or duration of stay at ICU.

Demographic characteristics of the study cohort were compared using using Mann-Whitney $U$ test (two groups) or Kruskal Wallis (>two groups) (continuous variables not normally distributed). Student's t test (two groups) or one-way ANOVA (>two groups) were used to compare means (continuous variables with normal distribution).

As planned, patients were classified according to sepsis status (sepsis without vs sepsis with shock), AKI status (no AKI vs transient AKI vs intrinsic AKI) and tertiles of CRP and APACHE II score for comparison.

Dichotomous variables were compared between groups using Chi square analysis.

Regression analysis was used to assess association between serum and urinary NGAL.

\section{Results}

Demographics and clinical background of the 107 included patients are presented in Tables 1 and 2 as partially published elsewhere [25] (Tables 1 and 2). Sepsis without shock was present in 42 (39.3\%) patients and sepsis with shock in $65(60.7 \%)$ patients. Twenty-eight (26.2\%) patients were classified as having no AKI versus $57(53.3 \%)$ and $22(20.6 \%)$ as having transient and intrinsic AKI, respectively. Median APACHE II score was 21 in sepsis patients without shock and 23 in those with shock $(\mathrm{P}=0.22)$ and increased from no AKI over transient AKI to intrinsic AKI $(\mathrm{P}=0.08)$.

Table 1 Clinical and demographic characteristics of the cohort comparing no-AKI vs transient AKI vs intrinsic AKI

\begin{tabular}{|c|c|c|c|c|}
\hline & no AKI $(n=28)$ & Transient AKI $(n=57)$ & Intrinsic AKI $(n=22)$ & $\mathrm{p}$ value \\
\hline Gender male (\%) & 51.7 & 54.4 & 59.1 & 0.93 \\
\hline Age (years,mean/sd) & $55.4(17.3)$ & $62.6(13.2)$ & $63.1(14.9)$ & 0.08 \\
\hline Reason for admission (\%): & & & & 0.11 \\
\hline Respiratory & 46.4 & 38.6 & 36.4 & \\
\hline Abdominal & 21.4 & 33.3 & 36.4 & \\
\hline Urinary & 7.1 & 8.8 & 0 & \\
\hline Endocarditis & 3.6 & 7.0 & 0 & \\
\hline Neurological & 7.1 & 0 & 4.5 & \\
\hline Catheter & 10.7 & 1.8 & 0 & \\
\hline Other & 3.6 & 10.5 & 22.7 & \\
\hline CKD on admission (eGFR according to MDRD <60 mL/min/1,73 m2) (\%) & 10.7 & 8.8 & 9.1 & 1 \\
\hline APACHE II score on the first day of admission & $21(10)$ & 22(8) & $24.5(9)$ & 0.08 \\
\hline Fluid balance first 24 hours (liter, mean/sd) & $2.2(1.8)$ & $3.1(1.9)$ & $5.4(2.7)$ & $<0.001$ \\
\hline Use of diuretics on the first day of admission (\%) & 7.1 & 14 & 22.7 & 0.29 \\
\hline RRT need during ICU stay (\%) & 0 & 1.8 & 59.1 & $<0.001$ \\
\hline Vasopressor use (\%) & 32.1 & 61.4 & 86.4 & $<0.001$ \\
\hline Total dose of noradrenaline first $24 \mathrm{~h}$ in $\mu \mathrm{g} / \mathrm{kg} / \mathrm{min}$ (mean $/ \mathrm{sd}$ ) & $0.05(0.11)$ & $0.09(0.12)$ & $0.20(0.22)$ & 0.001 \\
\hline $\begin{array}{l}\text { Maximum dose of noradrenaline during first } 24 \mathrm{~h} \\
\text { in } \mu \mathrm{g} / \mathrm{kg} / \mathrm{min} \text { (mean/sd) }\end{array}$ & $0.12(0.23)$ & $0.25(0.31)$ & $0.54(0.55)$ & 0.008 \\
\hline Need for ventilation during ICU stay (\%) & 39.3 & 50.9 & 86.4 & 0.002 \\
\hline LOS in the ICU (days) & $5(6)$ & $5(10)$ & $38(32)$ & 0.014 \\
\hline ICU mortality (\%) & 21.4 & 15.8 & 54.2 & 0.002 \\
\hline Mortality at 90 days (\%) & 28.6 & 24.6 & 59.1 & 0.012 \\
\hline
\end{tabular}


Table 2 Clinical and demographic characteristics of the cohort comparing sepsis patients without vs with shock

\begin{tabular}{|c|c|c|c|}
\hline & Sepsis without shock $(n=42)$ & Sepsis with shock $(n=65)$ & $\mathrm{p}$ value \\
\hline Gender male (\%) & 50 & 60 & 0.31 \\
\hline Age (years,mean/sd) & $57.6(15.6)$ & $62.9(14.3)$ & 0.16 \\
\hline Reason for admission (\%): & & & 0.02 \\
\hline Respiratory & 47.6 & 35.4 & \\
\hline Abdominal & 14.3 & 41.5 & \\
\hline Urinary & 14.3 & 1.5 & \\
\hline Endocarditis & 2.4 & 6.2 & \\
\hline Neurological & 4.8 & 1.5 & \\
\hline Catheter & 4.8 & 3.1 & \\
\hline Other & 11.9 & 10.8 & \\
\hline CKD on admission (MDRD $<60 \mathrm{~mL} / \mathrm{min} / 1,73 \mathrm{~m} 2$ ) (\%) & 16.7 & 4.6 & 0.04 \\
\hline APACHE I| score on the first day of admission & $21(9)$ & 23(9) & 0.22 \\
\hline AKI (transient or intrinsic) (\%) & $25(59.5)$ & $54(83.1)$ & 0.007 \\
\hline Fluid balance first 24 hours (liter, mean/sd) & $2.06(2.21)$ & $3.8(2.58)$ & $<0.001$ \\
\hline Use of diuretics on the first day of admission (\%) & 9.5 & 16.9 & 0.28 \\
\hline RRT need during ICU stay (\%) & 0 & 21.5 & 0.001 \\
\hline Total dose of noradrenaline first $24 \mathrm{~h}$ in $\mu \mathrm{g} / \mathrm{kg} / \mathrm{min}$ (mean $/ \mathrm{sd}$ ) & N/A & $0.17(0.16)$ & N/A \\
\hline Maximum dose of noradrenaline during first $24 \mathrm{~h}$ in $\mu \mathrm{g} / \mathrm{kg} / \mathrm{min}$ (mean $/ \mathrm{sd}$ ) & N/A & $0.44(0.41)$ & N/A \\
\hline Need for ventilation during ICU stay (\%) & 39.3 & 73.8 & $<0.001$ \\
\hline LOS in the ICU (days) & $4(6)$ & $7(16)$ & 0.03 \\
\hline ICU mortality (\%) & 14.3 & 32.3 & 0.04 \\
\hline Mortality at 90 days (\%) & 19.0 & 41.5 & 0.02 \\
\hline
\end{tabular}

More sepsis patients with shock versus without shock had transient or intrinsic AKI (35/65 vs 22/42 and 19/65 vs $3 / 42$, respectively, $\mathrm{P}=0.007)$. There was also an increasing positive fluid balance, need for ventilation, length of ICU stay and mortality from no AKI over transient AKI to intrinsic AKI and in patients with versus those without shock. Fourteen patients needed RRT (Tables 1 and 2).

Median urinary and serum NGAL levels were higher in sepsis patients with versus those without shock (Figure 1A, B, C and Table 3). All no AKI patients had serum NGAL levels above the generally accepted cut-off of $150 \mathrm{ng} / \mathrm{mL}$ $[26,27]$ at all time points. All sepsis patients with shock had urinary NGAL levels above $150 \mathrm{ng} / \mathrm{mL}$ at admission and four hours later, even if they did not have AKI. Urinary and serum NGAL levels were higher in intrinsic versus transient and no AKI patients, but there was substantial overlap limiting discriminative value (Table 3 ). When classified according to sepsis without versus with shock, discriminative value of NGAL for AKI further decreased (Figure 2A, B and C).

Urinary and serum NGAL levels increased with tertiles of CRP (175 ng/mL vs $229 \mathrm{ng} / \mathrm{mL}$ vs $563 \mathrm{ng} / \mathrm{mL}$, for uNGAL and $245 \mathrm{ng} / \mathrm{mL}$ vs $296 \mathrm{ng} / \mathrm{mL}$ vs $512 \mathrm{ng} / \mathrm{mL}$ for
sNGAL ( $\mathrm{P}=0.006$ and $\mathrm{P}=0.04$, respectively) (Figure 3A and $B)$. Neither uNGAL or SNGAL had a discriminative value for differentiating AKI (transient or intrinsic) from no AKI (Figure $3 \mathrm{C}$ and D).

We found a strong correlation between sNGAL and uNGAL, both in patients without and with AKI $\left(R^{2}=0.38\right.$ for no $A K I$ and $R^{2}=0.31$ for $\left.A K I\right)$, but with different relationships in no AKI $\left(Y=0.87^{*} X+20.1\right)$ versus $A K I$ $\left(\mathrm{Y}=0.87^{*} \mathrm{X}+314.3\right)$, respectively $(\mathrm{P}<0.001)$. The slopes of the regression lines followed a parallel course (Figure 4).

Analyses of the correlation between sNGAL and UNGAL levels at the other time points demonstrated comparable findings (data not shown).

There was also a correlation between the APACHE II score and UNGAL $(\mathrm{P}=0.002, \mathrm{P}<0.001$ and $\mathrm{P}=0.003$ at T0, T4 and T24) and between the APACHE II score and sNGAL $(\mathrm{P}=0.007, \mathrm{P}=0.003$ and $\mathrm{P}=0.07$ at $\mathrm{T} 0$,T4 and T24). Median urinary NGAL levels increased with increasing tertiles of APACHE II (179 ng/mL vs $355 \mathrm{ng} /$ $\mathrm{mL}$ vs $405 \mathrm{ng} / \mathrm{mL}$ for APACHE II $<20,20-25$ and $>25$ respectively, $\mathrm{P}=0.04$ ) (Figure 5 ). There was an increasing trend in serum NGAL levels over the first two tertiles (Figure 5). 

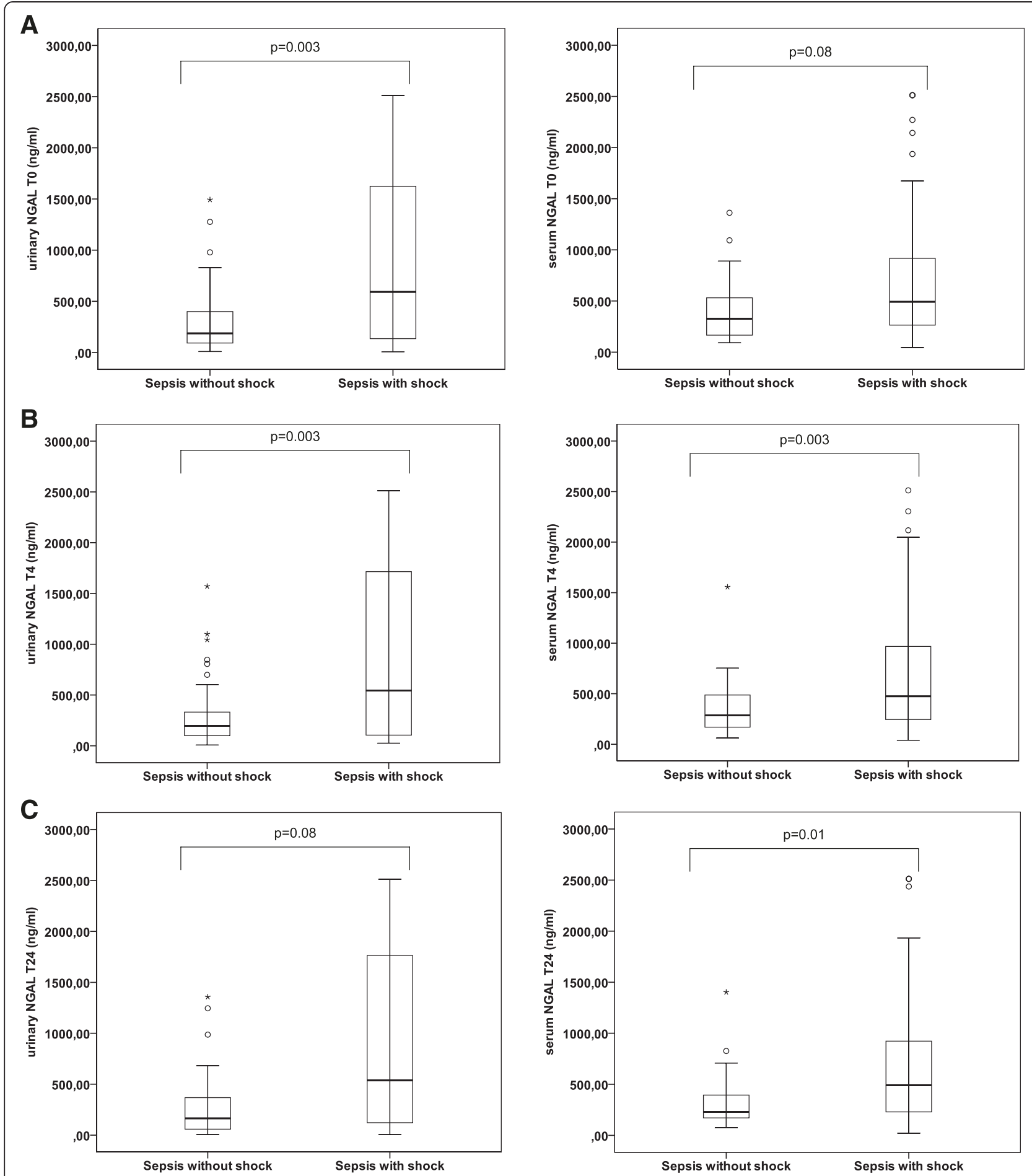

Figure 1 Urinary and serum NGAL in sepsis without vs with shock. A: Urinary NGAL (ng/mL) at time point T0 is higher in sepsis with vs without shock $(P=0.003)$. There is a trend for higher serum NGAL levels $(n g / m L)$ in sepsis with vs without shock $(P=0.083)$. B: Serum and urinary NGAL ( $\mathrm{ng} / \mathrm{mL}$ ) at time point T4 are higher in sepsis with shock vs without shock (both $\mathrm{P}=0.003)$. C: Serum NGAL (ng/mL) at time point T24 is higher in sepsis with vs without shock $(P=0.011)$. There is a trend for higher urinary NGAL levels $(\mathrm{ng} / \mathrm{ml})$ in sepsis with vs without shock $(\mathrm{P}=0.082) .\left({ }^{\circ}=\right.$ outliers $^{*}{ }^{*}=$ extreme outliers ( $>$ three times the height of the boxes)). 
Table 3 Urinary NGAL and serum NGAL $(\mathrm{ng} / \mathrm{mL})$ in no AKI vs transient and intrinsic AKI

\begin{tabular}{|c|c|c|c|c|c|c|c|c|c|}
\hline & \multicolumn{3}{|c|}{ Sepsis without shock } & \multirow[b]{2}{*}{$p$ value } & \multicolumn{3}{|c|}{ Sepsis with shock } & \multirow[b]{2}{*}{$p$ value } & \multirow[b]{2}{*}{$\begin{array}{l}\text { Overall } \\
p \text { value }\end{array}$} \\
\hline & $\begin{array}{l}\text { No AKI } \\
(n=17)\end{array}$ & $\begin{array}{l}\text { Transient } \\
\text { AKI }(n=22)\end{array}$ & $\begin{array}{l}\text { Intrinsic } \\
\text { AKI }(n=3)\end{array}$ & & $\begin{array}{l}\text { No AKI } \\
(n=11)\end{array}$ & $\begin{array}{l}\text { Transient } \\
\text { AKI }(n=35)\end{array}$ & $\begin{array}{l}\text { Intrinsic } \\
\text { AKI }(n=19)\end{array}$ & & \\
\hline UNGAL TO & $125(262)$ & $262(350)$ & 1276 & $0.27^{*}$ & $178(457)$ & 649(1164) & 1775(2108) & $0.08^{*}$ & $0.001^{\#}$ \\
\hline uNGAL T4 & $116(256)$ & $234(310)$ & 1044 & $0.27^{*}$ & $269(511)$ & $523(1384)$ & 1802(2046) & $0.03^{*}$ & $0.009^{\#}$ \\
\hline uNGAL T24 & $122(218)$ & 239(383) & 1245 & $0.27^{*}$ & $137(612)$ & 405(1523) & 2372(2308) & $0.11^{*}$ & $0.084^{\#}$ \\
\hline sNGAL TO & $220(269)$ & $288(477)$ & 235 & $0.44^{*}$ & $290(221)$ & 493(579) & 962(894) & $0.003^{*}$ & $0.03^{\#}$ \\
\hline sNGAL T4 & 218(193) & $336(338)$ & 284 & $0.17^{*}$ & $267(192)$ & $469(604)$ & 975(940) & $0.011^{*}$ & $0.002^{\#}$ \\
\hline sNGAL T24 & 203(189) & 295(364) & 184 & $0.44^{*}$ & 283(188) & $475(435)$ & $1052(670)$ & $0.001^{*}$ & $0.001^{\#}$ \\
\hline
\end{tabular}

*P-values refer to the difference between no AKI, transient AKI and intrinsic AKI, separately for patients with vs without shock.

\#P-values refer to the difference between no AKI, transient AKI and intrinsic AKI either with or without shock at each time point.

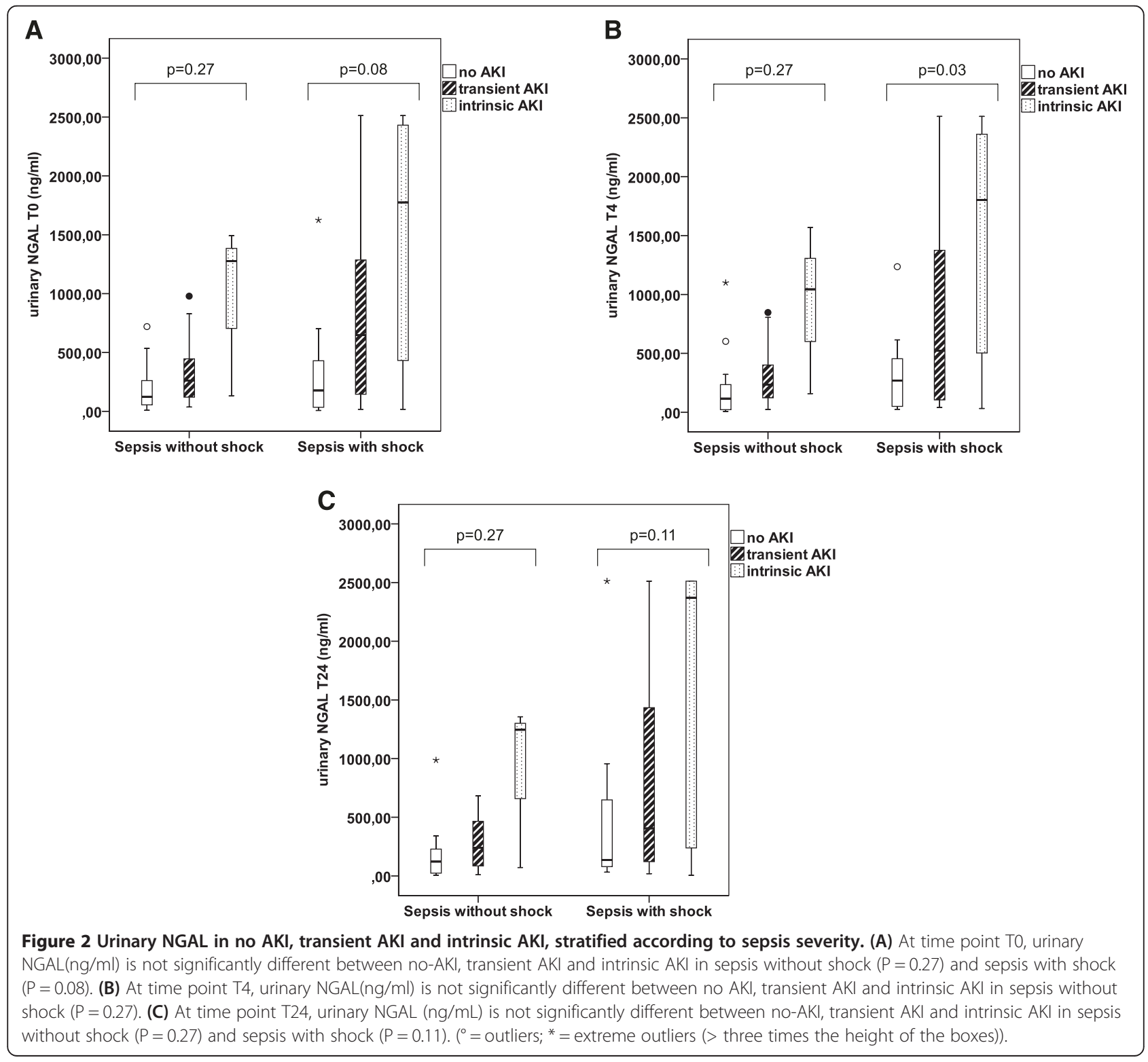




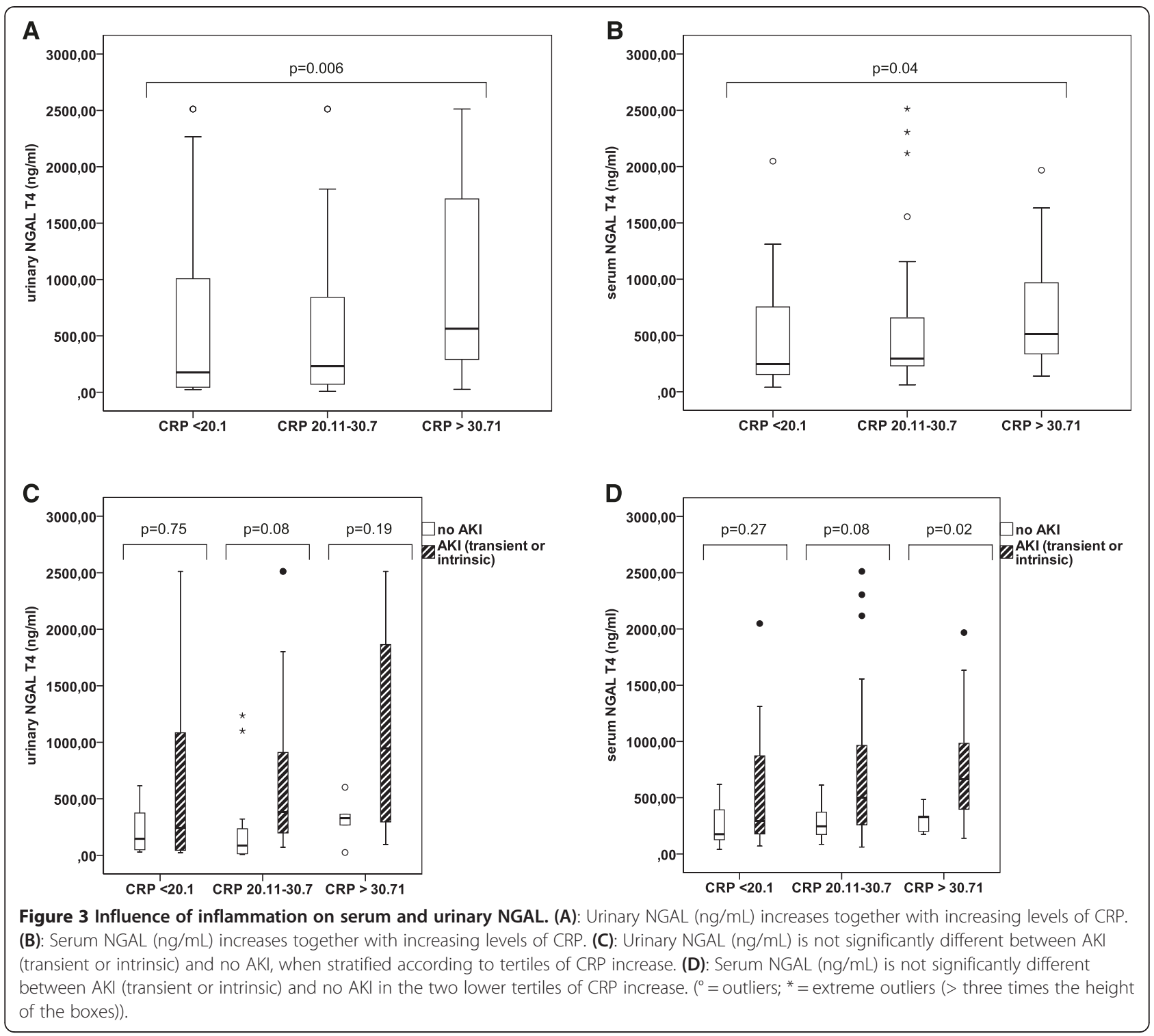

\section{Discussion}

In this cohort of septic ICU patients, we confirmed that the risk for AKI increased with severity of sepsis. Serum and urinary levels of NGAL increased with severity of illness and inflammation, as assessed by APACHE II and CRP. In addition, there was a strong correlation between urinary and serum levels of NGAL, irrespective of presence of AKI. Although there was a significant difference in uNGAL levels between no AKI, transient AKI and intrinsic AKI, this difference did not remain when patients were stratified according to severity of sepsis (sepsis with or without shock) and to tertiles of CRP or APACHE II score increase, except for sNGAL in the highest CRP tertile where a significant difference between AKI and no AKI could be found. However, across all tertiles, there was an important overlap in NGAL levels between AKI and no AKI, the result being that NGAL is not a reliable biomarker to discriminate between AKI and no AKI in the individual case.

It remains unclear whether in sepsis patients, increased urinary NGAL is a marker of structural tubular injury, the result of overspill from the systemic circulation or just a marker of severity of illness. This is also emphasized by the fact that no commercially available assays make a distinction between 'renal' NGAL and 'neutrophil' NGAL. Cai et al. confirmed that NGAL is present in different forms in the urine by using five ELISAs (using different monoclonal and polyclonal antibodies) and one polyclonal-based RIA [11]. Authors concluded that it should be possible to construct an assay that preferentially identifies NGAL originating from the tubular epithelium or the neutrophils. Martensson et al. demonstrated that the ratio of two ELISAs, 


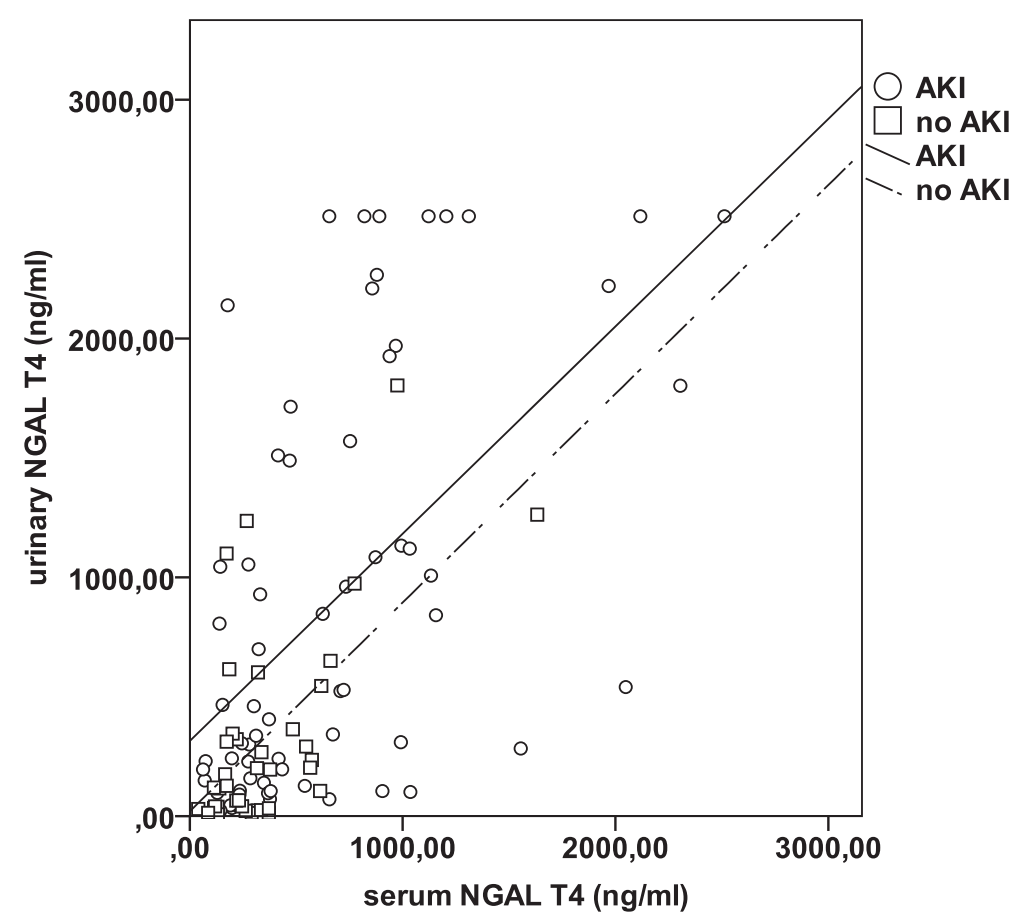

Figure 4 Linear regression between serum NGAL and urinary NGAL in no AKI and AKI. For no AKl: $y=0.87^{*} x+20.1$ and for AKl: $y=0.87^{*} x+314.3$ $R^{2}$ for $A K l=0.31$ and $R 2$ for no-AKl $=0.38(P<0.001)$.

each using a different monoclonal antibody, could detect the monomeric form (which mainly originates from renal tubular cells) with an AUC ROC of 0.92 in ICU patients without CKD [13]. However, more recently, Glassford et al. assessed monomeric and dimeric uNGAL contribution using western blotting-validated enzymelinked immunosorbent assays and their calculated ratio in 102 patients with SIRS and found that at best, urinary forms of NGAL are fair predictors of renal or patients outcome. The authors conclude that the nature and source of uNGAL are complex and challenge the utility of NGAL as a uniform biomarker [12].

NGAL is filtered into the primary urine and almost completely reabsorbed by the tubular epithelium via the megalin receptor under normal circumstances [28]. One of the concerns of using NGAL as a biomarker for AKI is that even in the absence of AKI, NGAL levels can increase during inflammation [18,29-33]. We demonstrated that in patients with sepsis, serum NGAL levels increase in parallel with the severity of sepsis, severity of illness and severity of inflammation and thus increased levels might not automatically reflect tubular damage.

High levels of serum NGAL can overwhelm the reabsorbing capacity of the proximal tubule so that urinary NGAL levels might increase, even in the absence of structural tubular injury. We found a strong correlation between serum and urinary NGAL levels, both in patients without and with AKI. The value of urinary NGAL for differentiating between AKI and no AKI was also low due to overlap between the two groups, irrespective of severity of illness, sepsis or inflammation.

These findings underline that the concept of "subclinical AKI" should be used with caution, however, they do not contradict the existence of this concept in certain patients. Indeed, urinary NGAL was well correlated with serum NGAL $\left(R^{2}=0.37\right)$, but the regression line went through the origin for no AKI patients, whereas it did not in AKI patients. This suggests that in AKI, there is some degree of either local tubular production or reduced reabsorption, both of which may reflect tubular injury.

In any case, our data indicate that the suggestion to use uNGAL as a diagnostic marker because of its allegedly discriminating role in differentiating AKI from no AKI should be carefully considered, at least in patients with sepsis. In addition, when including patients with 'subclinical AKI', based on NGAL positivity only, in an interventional trial, those interventions that only focus on preventing or healing tubular injury risk to be less useful. The latter because, in a substantial part of patients, the increased urinary NGAL will not be the result of tubular damage but rather of overspill from the circulation as a consequence of high circulating levels induced by inflammation.

Designing an immunoassay that perfectly discriminates between monomer and dimer NGAL will only partly solve 


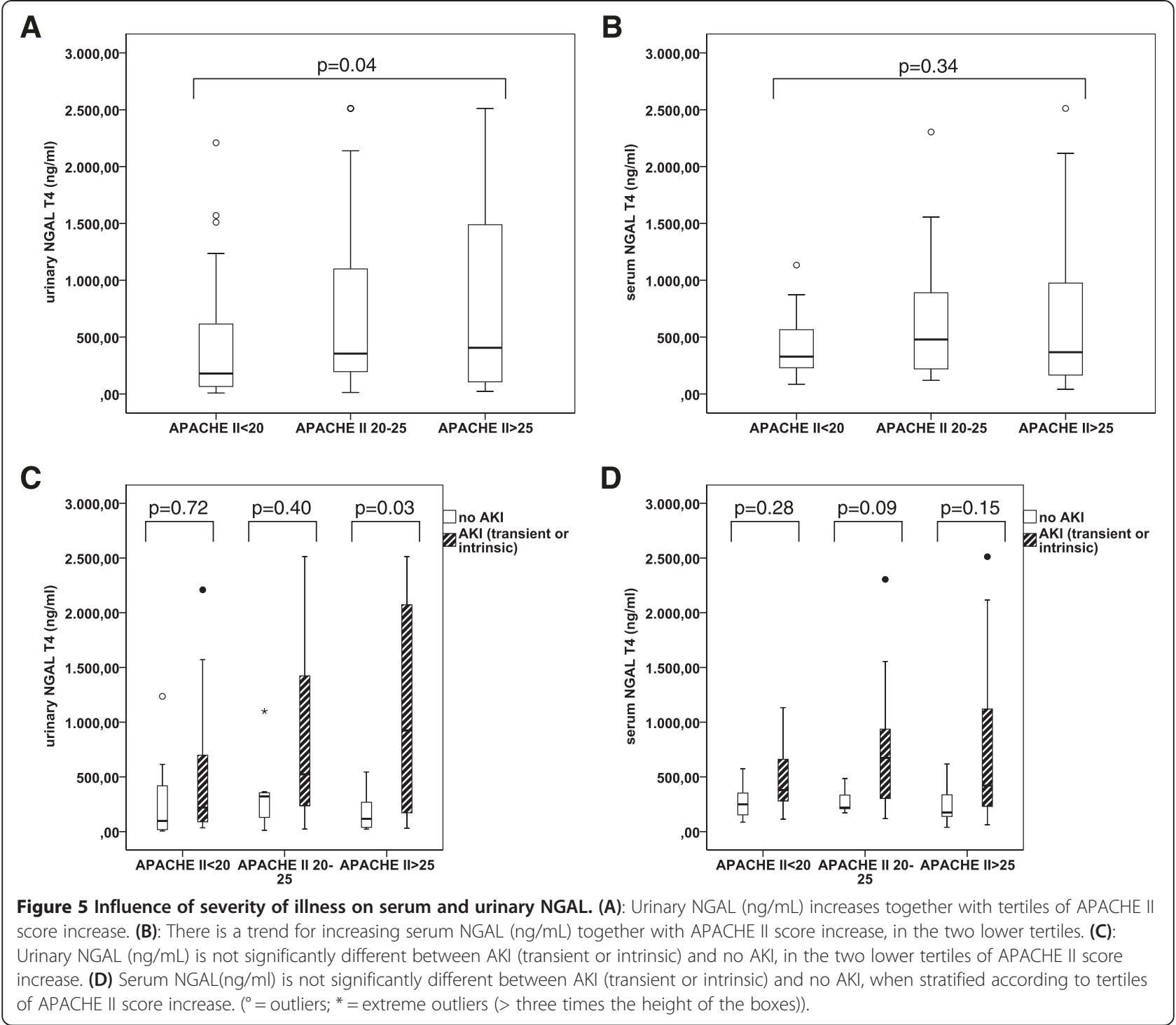

this issue. Since the common pathway in CKD relates to tubulointerstitial damage which in turn could imply high levels of monomer NGAL, a tool that allows the measurement of monomer NGAL only, would not be helpful in differentiating between AKI, acute on chronic kidney disease and CKD. Also, the role of leukocytes in the pathophysiology of septic AKI is being increasingly recognized [34]. So the presence of dimer NGAL can also be an indication of local tubular damage rather than just being a sign of glomerular overflow or presence of leukocyturia in the context of urinary infection.

A limitation of this observational study is that it describes a relatively small cohort of septic patients. However, to our knowledge, this is the first study providing information on prospectively collected serum and urinary NGAL levels at different time points during the first 24 hours after admission in septic patients.

\section{Conclusions}

In patients with sepsis, levels of urinary and serum NGAL and the prevalence and severity of AKI are strongly associated with severity of illness and inflammation as expressed by APACHE II and CRP. There is a strong correlation in sepsis patients between serum and urinary levels of NGAL, irrespective of presence of AKI. Therefore, the conclusion that presence of NGAL in the urine implies tubular injury should be made very cautiously in sepsis patients.

\section{Abbreviations}

AKI: Acute kidney injury; APACHE II score: Acute physiology and chronic health evaluation II score; CRP: C-reactive protein; CKD: Chronic kidney disease; eGFR: Estimated glomerular filtration ratio; ICU: Intensive care unit; LOS: Length of stay; MDRD: Modification of Diet in Renal Disease;

NGAL: Neutrophil gelatinase-associated lipocalin; RIFLE: Risk, Injury, Failure, Loss of kidney function and End-stage renal disease; RRT: Renal replacement therapy. 


\section{Competing interests}

The authors declare that they have no competing interests.

\section{Authors' contributions}

WB designed the study, performed the statistical analyses and helped draft the manuscript. JV assembled the patients, collected and analyzed the data and wrote the manuscript. GG carried out the immunoassays and critically reviewed the manuscript. $\mathrm{NL}, \mathrm{EH}, \mathrm{AD}$ and $\mathrm{RV}$ helped writing the draft and critically reviewed it. All authors read and approved the final manuscript.

\section{Acknowledgements}

The authors thank A De Jonghe, MA Waterloos, M Van Landschoot, C Danneels and B Martens for their technical assistance.

\section{Author details}

${ }^{1}$ Renal Division, Ghent University Hospital, Ghent, Belgium. ${ }^{2}$ Intensive Care Unit, Ghent University Hospital, Ghent, Belgium. ${ }^{3}$ Research Foundation Flanders, Flanders, Belgium.

\section{Received: 9 October 2014 Accepted: 22 January 2015}

\section{Published online: 13 February 2015}

\section{Reference}

1. Bagshaw SM, Uchino S, Bellomo R, Morimatsu H, Morgera S, Schetz M, et al. Septic acute kidney injury in critically ill patients: clinical characteristics and outcomes. Clin J Am Soc Nephrol. 2007:2:431-9.

2. Matejovic $M$, Radermacher $P$, Joannidis $M$. Acute kidney injury in sepsis: is renal blood flow more than just an innocent bystander? Intensive Care Med. 2007;33:1498-500.

3. Molitoris BA. Renal blood flow in sepsis: a complex issue. Crit Care. 2005;9:327-8

4. Wan $L$, Bellomo R, Di GD, Ronco C. The pathogenesis of septic acute renal failure. Curr Opin Crit Care. 2003;9:496-502.

5. Wang Z, Holthoff JH, Seely KA, Pathak E, Spencer III HJ, Gokden N, et al. Development of oxidative stress in the peritubular capillary microenvironment mediates sepsis-induced renal microcirculatory failure and acute kidney injury. Am J Pathol. 2012;180:505-16.

6. Zarjou A, Agarwal A. Sepsis and acute kidney injury. [Review]. J Am Soc Nephrol. 2011;22:999-1006.

7. Cruz DN, Ricci Z, Ronco C. Clinical review: RIFLE and AKIN-time for reappraisal. Crit Care. 2009;13:211

8. Doi K, Yuen PS, Eisner C, Hu X, Leelahavanichkul A, Schnermann J, et al. Reduced production of creatinine limits its use as marker of kidney injury in sepsis. J Am Soc Nephrol. 2009;20:1217-21.

9. Endre $\mathrm{ZH}$, Westhuyzen J. Early detection of acute kidney injury: emerging new biomarkers. Nephrology (Carlton). 2008;13:91-8.

10. Haase M, Bellomo R, Devarajan P, Schlattmann P, Haase-Fielitz A. Accuracy of neutrophil gelatinase-associated lipocalin (NGAL) in diagnosis and prognosis in acute kidney injury: a systematic review and meta-analysis. Am J Kidney Dis. 2009;54:1012-24.

11. Cai L, Rubin J, Han W, Venge P, Xu S. The origin of multiple molecular forms in urine of HNL/NGAL. Clin J Am Soc Nephrol. 2010;5:2229-35.

12. Glassford NJ, Schneider AG, Xu S, Eastwood GM, Young H, Peck L, et al. The nature and discriminatory value of urinary neutrophil gelatinase-associated lipocalin in critically ill patients at risk of acute kidney injury. Intensive Care Med. 2013;39:1714-24.

13. Martensson J, Xu S, Bell M, Martling CR, Venge P. Immunoassays distinguishing between $\mathrm{HNL} / \mathrm{NGAL}$ released in urine from kidney epithelial cells and neutrophils. Clin Chim Acta. 2012;413:1661-7.

14. Doi K, Katagiri D, Negishi K, Hasegawa S, Hamasaki Y, Fujita T, et al. Mild elevation of urinary biomarkers in prerenal acute kidney injury. Kidney Int. 2012;82:1114-20.

15. Nejat M, Pickering JW, Devarajan P, Bonventre JV, Edelstein $C L$, Walker RJ, et al. Some biomarkers of acute kidney injury are increased in pre-renal acute injury. Kidney Int. 2012;81:1254-62.

16. Haase M, Kellum JA, Ronco C. Subclinical AKI-an emerging syndrome with important consequences. Nat Rev Nephrol. 2012;8:735-9.

17. Ronco C, Kellum JA, Haase M. Subclinical AKI is still AKI. Crit Care. 2012;16:1-4.

18. Giasson J, Li GH, Chen Y. Neutrophil gelatinase-associated lipocalin (NGAL) as a new biomarker for non-acute kidney injury (AKI) diseases. Inflamm Allergy Drug Targets. 2011;10:272-82.

19. Axelsson L, Bergenfeldt M, Ohlsson K. Studies of the release and turnover of a human neutrophil lipocalin. Scand J Clin Lab Invest. 1995;55:577-88.
20. Mori K, Lee HT, Rapoport D, Drexler IR, Foster K, Yang J, et al. Endocytic delivery of lipocalin-siderophore-iron complex rescues the kidney from ischemia-reperfusion injury. J Clin Invest. 2005;115:610-21.

21. Schmidt-Ott KM, Mori K, Li JY, Kalandadze A, Cohen DJ, Devarajan P, et al. Dual action of neutrophil gelatinase-associated lipocalin. J Am Soc Nephrol. 2007;18:407-13.

22. Anonymous. American College of Chest Physicians/Society of Critical Care Medicine Consensus Conference: definitions for sepsis and organ failure and guidelines for the use of innovative therapies in sepsis. Crit Care Med. 1992;20:864-74.

23. Bellomo R, Ronco C, Kellum JA, Mehta RL, Palevsky P. Acute renal failure definition, outcome measures, animal models, fluid therapy and information technology needs: the Second International Consensus Conference of the Acute Dialysis Quality Initiative (ADQI) Group. Crit Care. 2004;8:R204-12.

24. Macedo E, Malhotra R, Claure-Del GR, Fedullo P, Mehta RL. Defining urine output criterion for acute kidney injury in critically ill patients. Nephrol Dial Transplant. 2011;26:509-15.

25. Vanmassenhove J, Glorieux G, Hoste E, Dhondt A, Vanholder R, Van BW. Urinary output and fractional excretion of sodium and urea as indicators of transient versus intrinsic acute kidney injury during early sepsis. Crit Care. 2013;17:1-10.

26. Di SS, Magrini L, De BB, Marino R, Ferri E, Moscatelli $P$, et al. Additive value of blood neutrophil gelatinase-associated lipocalin to clinical judgement in acute kidney injury diagnosis and mortality prediction in patients hospitalized from the emergency department. Crit Care. 2013;17:R29.

27. Shapiro NI, Trzeciak S, Hollander JE, Birkhahn R, Otero R, Osborn TM, et al. The diagnostic accuracy of plasma neutrophil gelatinase-associated lipocalin in the prediction of acute kidney injury in emergency department patients with suspected sepsis. Ann Emerg Med. 2010;56:52-9.

28. Hvidberg V, Jacobsen C, Strong RK, Cowland JB, Moestrup SK, Borregaard N. The endocytic receptor megalin binds the iron transporting neutrophilgelatinase-associated lipocalin with high affinity and mediates its cellular uptake. FEBS Lett. 2005;579:773-7.

29. Bagshaw SM, Bennett M, Haase M, Haase-Fielitz A, Egi M, Morimatsu H, et al. Plasma and urine neutrophil gelatinase-associated lipocalin in septic versus non-septic acute kidney injury in critical illness. Intensive Care Med. 2010;36:452-61.

30. Martensson J, Bell M, Oldner A, Xu S, Venge P, Martling CR. Neutrophil gelatinase-associated lipocalin in adult septic patients with and without acute kidney injury. Intensive Care Med. 2010;36:1333-40.

31. Wheeler DS, Devarajan P, Ma Q, Harmon K, Monaco M, Cvijanovich N, et al. Serum neutrophil gelatinase-associated lipocalin (NGAL) as a marker of acute kidney injury in critically ill children with septic shock. Crit Care Med. 2008;36:1297-303.

32. Hur M, Kim H, Lee $S$, Cristofano F, Magrini $L$, Marino $R$, et al. Diagnostic and prognostic utilities of multimarkers approach using procalcitonin, B-type natriuretic peptide, and neutrophil gelatinase-associated lipocalin in critically ill patients with suspected sepsis. BMC Infect Dis. 2014;14:224.

33. Kim H, Hur M, Cruz DN, Moon HW, Yun YM. Plasma neutrophil gelatinaseassociated lipocalin as a biomarker for acute kidney injury in critically ill patients with suspected sepsis. Clin Biochem. 2013:46:1414-8.

34. Jang HR, Rabb H. Immune cells in experimental acute kidney injury. Nat Rev Nephrol. 2015;11(2):88-101.

\section{Submit your next manuscript to BioMed Central and take full advantage of:}

- Convenient online submission

- Thorough peer review

- No space constraints or color figure charges

- Immediate publication on acceptance

- Inclusion in PubMed, CAS, Scopus and Google Scholar

- Research which is freely available for redistribution 